\title{
Research on the Influence of Piston Constraint on the Temperature Field of Multi-disc Clutch
}

\author{
Jie Zhang and Tieshan Zhang \\ School of Mechanical Engineering, Nanjing University of Science and Technology, Nanjing, 210094, P.R.China
}

\begin{abstract}
The two-dimensional finite element model of multi-disc clutch friction pair was established by Abaqus simulation software, and the contact pressure of the friction surface under different piston constraints was calculated and analyzed. Considering contact pressure as the main heat-generating factor, the two-dimensional heat conduction process was numerically discretized by the implicit difference method. Then the temperature model of the multi-disc clutch friction pair was programmed in Matlab. The bench test verified the correctness of the temperature model. It is found that the temperature field between components is different and shows uneven distribution under the actual constraint. The local temperature of the component near the concentrated load is the highest, in which the radial temperature difference is the largest. The arrangement in which the piston pressure is concentrated in middle diameter produces the lowest temperature and the smallest radial temperature difference, which can effectively avoid thermal deformation of the component due to uneven temperature distribution.
\end{abstract}

\section{Introduction}

The wet multi-disc clutch relies on multiple friction pairs to transmit torque and brings the benefits of large engagement torque, reliable operation and stable wear, while causes a large amount of friction heat generated by the clutch during the shifting. The heat capacity of the cooling lubricant and the heat sink of the plate are limited. Therefore, the failure mode of the wet multi-disc clutch is usually a high temperature caused by excessive temperature rise and uneven heat flux distribution.

Scholars have carried out a lot of research on the problem of friction pair temperature field. The threedimensional multi-disc friction pair temp-displacement coupling analysis was computationally intensive and time-consuming. At present, the research mainly simplifies the problem into three-dimensional single-sub model, two-dimensional axisymmetric model and semiinfinite thickness model, etc.. Analysis 1-4. Jinle Zhang 5 established a three-dimensional finite element model of the friction pair in Abaqus, and analyzed the influence of the relative rotational speed difference, the thickness of the plate and oil pressure on the temperature field and stress field. This model simplifies a plurality of friction pairs into a single pair. Zeyin He 6 considered the friction between the inner and outer teeth of the disc and the shell. It was considered that the positive pressure distribution between the friction discs of the wet multi-disc clutch is proportionally decreasing, and model was established by ANSYS. He found that the temperature distribution of the friction pairs of each piece is different, but ignoring the effects of circlip constraints.
In the actual structure of the vehicle clutch, the circlip or the clutch support plate is usually used to support and restrain the side of the friction pair, and the pressure piston plates are different in form, so the pressure is unevenly distributed, and it is necessary to explore the effect of the constraint application position on the temperature field.

\section{Multi-disc clutch friction system}

The diagram of the multi-disc clutch friction system is shown in Fig. 1. The system consists of the piston, separate plates, friction discs, the adjusting steel plate and the circlip. The friction disc consists of a chip and two linings. The material of friction lining is Copperbased powder metallurgy(cu-pm), as shown in Table 1 .

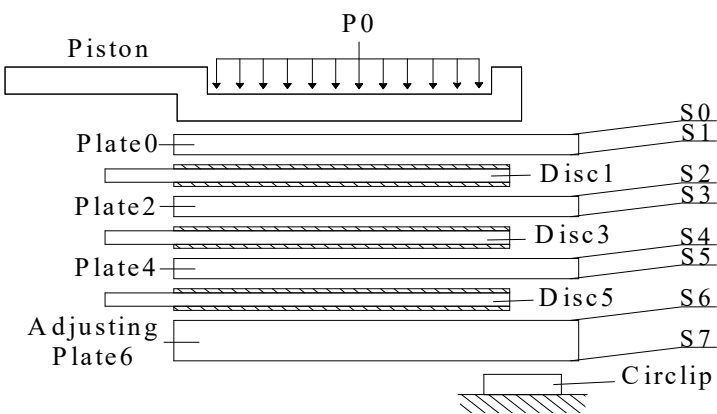

Fig. 1. Diagram of multi-disc clutch friction system. 
During the engagement, the uniform hydraulic pressure pushes the friction assembly to make axial movement.The circlip on the outer casing limits the axial displacement. As the clearance eliminated, the difference in rotational speed between the discs and the plates is eliminated to zero.

Table 1. Component materials and structural parameters.

\begin{tabular}{|c|c|c|c|c|}
\hline $\begin{array}{c}\text { Compo- } \\
\text { nent }\end{array}$ & $\begin{array}{c}\text { Inner } \\
\text { diameter } \\
\mathbf{d}_{\mathbf{i}} / \mathbf{m m}\end{array}$ & $\begin{array}{c}\text { Outer } \\
\text { diameter } \\
\mathbf{d}_{\mathbf{0}} / \mathbf{m m}\end{array}$ & $\begin{array}{c}\text { Thickne- } \\
\mathbf{s s ~ H / m m}\end{array}$ & Material \\
\hline Piston & 141.5 & 168 & 3.6 & $\begin{array}{c}\text { SPCC } \\
\text { steel }\end{array}$ \\
\hline $\begin{array}{c}\text { Separate } \\
\text { plate }\end{array}$ & 141.5 & 175.1 & 1.8 & $\begin{array}{c}\text { SPCC } \\
\text { steel }\end{array}$ \\
\hline $\begin{array}{c}\text { Friction } \\
\text { chip }\end{array}$ & 134.6 & 168 & 0.8 & $\begin{array}{c}\text { SPCC } \\
\text { steel }\end{array}$ \\
\hline $\begin{array}{c}\text { Friction } \\
\text { lining }\end{array}$ & 141.5 & 168 & 0.75 & cu-pm \\
\hline $\begin{array}{c}\text { Adjusti- } \\
\text { ng plate }\end{array}$ & 141.5 & 175.1 & 3.6 & $\begin{array}{c}\text { SPCC } \\
\text { steel }\end{array}$ \\
\hline Circlip & 164.8 & 172.8 & 1.8 & $\begin{array}{c}\text { SPCC } \\
\text { steel }\end{array}$ \\
\hline
\end{tabular}

\section{Contact pressure analysis}

The model is symmetric about the z-axis. So it is simplified to a two-dimensional axisymmetric model, as shown in Fig. 1. Starting from the piston, the number of the plates is $0,2,4$. The adjusting plate number is 6 . The discs number 1, 3, 5. The contact faces between the components are numbered S0 S6.

As shown in Fig. 2, the pressure distribution of each sliding surface is analyzed under the influence of the circlip and the piston. The model uses CAX4I, 4 node axisymmetric bilinear quadrilateral, and incompatible mode element.

It can be seen from Fig. 3 and 4, the pressure on each side of the multiple friction pairs is different, and is unevenly distributed under the action of the circlip and the piston. The maximum axial pressure difference is $0.0481 \mathrm{MPa}$, and the maximum radial pressure difference is $0.142 \mathrm{MPa}$, which is much greater than the piston pressure of $0.06 \mathrm{MPa}$. Therefore, the effect of multiple pairs and restriction of piston and circlip can not be ignored in thermal analysis of friction pairs.

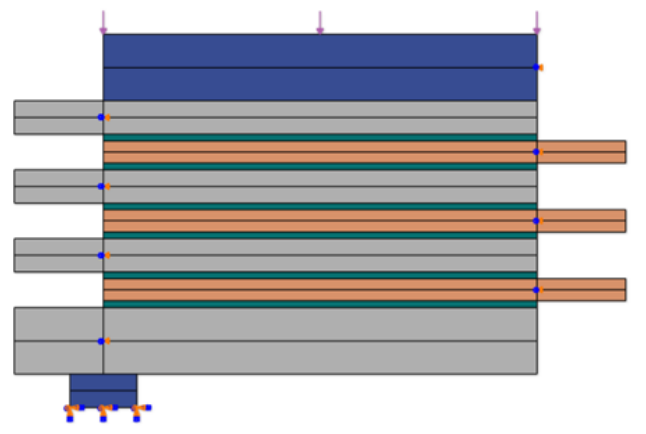

Fig. 2. Two-dimensional finite element model of multi-disc clutch.

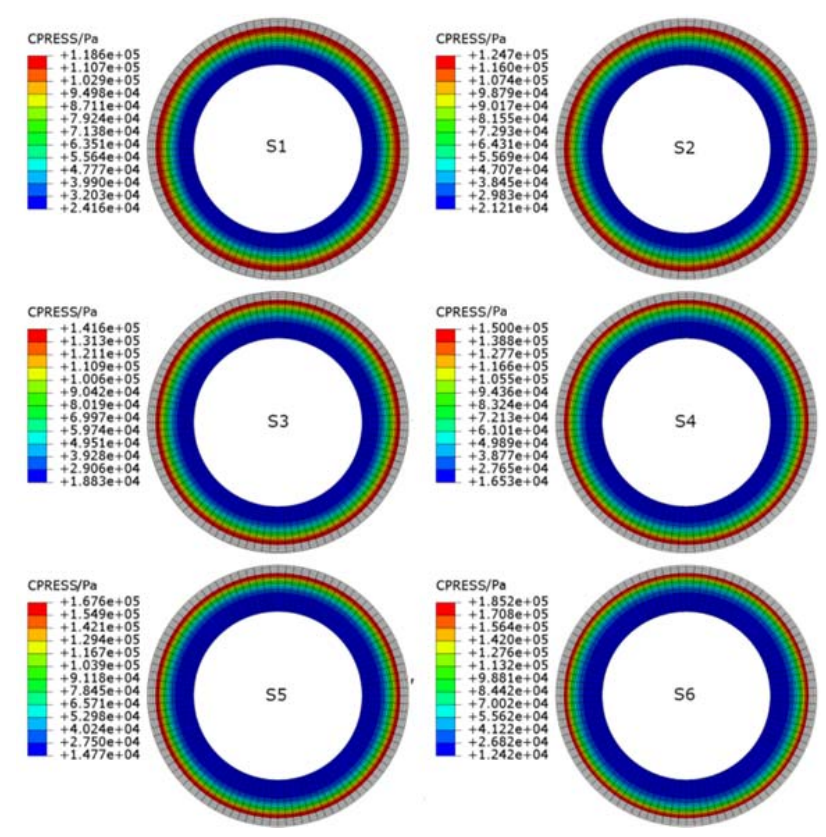

Fig. 3. Visualization results of surface contact pressure.

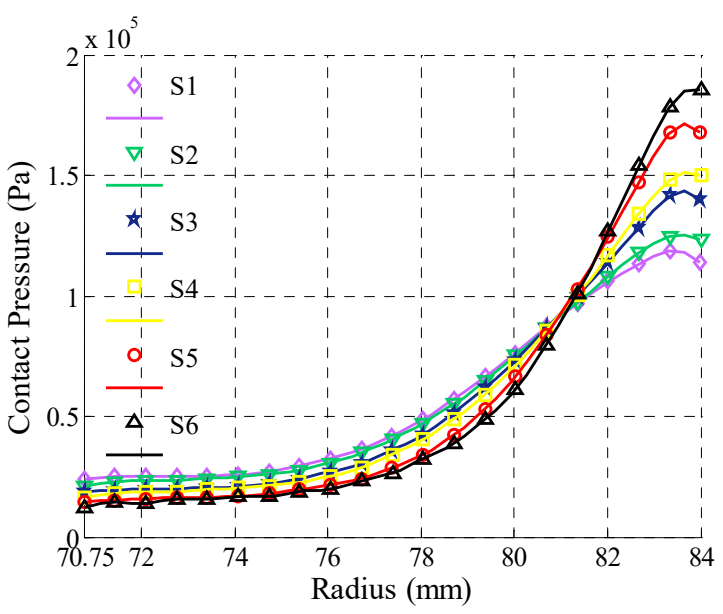

Fig. 4. Friction surface radial pressure curve.

\section{Heat transfer in multi-disc clutch}

The equation of two dimensional heat conduction is 7 :

$$
\rho C \frac{\partial T}{\partial t}=\lambda\left(\frac{\partial^{2} T}{\partial^{2}}+\frac{1}{r} \frac{\partial T}{\partial r}+\frac{\partial^{2} T}{\partial z^{2}}\right)
$$

where $\rho$ is the density, $C$ is the specific heat, $\lambda$ is the thermal conductivity, $T$ is the temperature, $r$ is the radial coordinate, $z$ is the axial coordinate, as shown in Table 2 .

The frictional contact surface heat flux is:

$$
q(r, t)=\eta \mu(\omega) P(r, t) \omega(t) r
$$

where $\eta$ is the conversion rate of friction work to heat, $\eta=1, \omega$ is the speed difference, $r$ is the radial position.

The coefficient of friction is 8 :

$$
\mu(\omega)=\mu_{k}+\left(\mu_{s}-\mu_{k}\right) e^{-\delta|\omega|}
$$

where the $\mu_{k}$ and $\mu_{s}$ are static and dynamic friction coefficient, 0.1 and 0.2 respectively, and $\delta=0.007$.

The heat flux entering the surface of each object is assigned by the heat transfer coefficient: 


$$
\gamma=\frac{q_{p}}{q_{d}}=\frac{\sqrt{\lambda_{p} \rho_{p} C_{p}}}{\sqrt{\lambda_{d} \rho_{d} C_{d}}}
$$

where subscript $p$ represents separate plate; subscript $d$ represents friciton disc.

$T_{\text {oil }}$ is oil temperature, $T_{0}$ is the initial temperature of each disc, $h_{i}, h_{o}, h_{p}$ and $h_{e}$ is the convection heat transfer coefficient of the inside faces, outside faces, grooveless surface of the plate, and equivalent grooves faces of the disc calculated by groove area to total area ratio, respectively 7.The boundary equations are:

$$
\begin{aligned}
& \text { plate: }\left.\quad \lambda_{p} \frac{\partial T}{\partial z}\right|_{z=z_{S_{2}}, z_{S_{4}}, z_{56}}=q_{p}(r, t)-h_{p}\left(T-T_{\text {oil }}\right) \\
& \text { plate: } \quad-\left.\lambda_{p} \frac{\partial T}{\partial z}\right|_{z=z_{S 1}, z_{S 3}, z_{S S}}=q_{p}(r, t)-h_{p}\left(T-T_{\text {oil }}\right) \\
& \text { disc: }\left.\quad \lambda_{d} \frac{\partial T}{\partial z}\right|_{z=z_{S 1}, z_{53}, z_{s 5}}=q_{d}(r, t)-h_{e}\left(T-T_{o i l}\right) \\
& \text { disc: } \quad-\left.\lambda_{d} \frac{\partial T}{\partial z}\right|_{z=z_{S 2}, z_{54}, z_{S 6}}=q_{d}(r, t)-h_{e}\left(T-T_{\text {oil }}\right) \\
& \text { piston: }\left.\quad \lambda_{p} \frac{\partial T}{\partial z}\right|_{z=z_{P S}}=-h_{p}\left[T-T_{\text {oil }}\right] \\
& \text { adjust : }\left.\quad \lambda_{p} \frac{\partial T}{\partial z}\right|_{z=z_{S 7}}=+h_{p}\left[T-T_{\text {oil }}\right] \\
& R=R_{i}:\left.\quad \lambda_{p, d} \frac{\partial T}{\partial r}\right|_{r=r_{i}}=+h_{i}\left[T-T_{\text {oil }}\right] \\
& R=R_{o}:\left.\quad \lambda_{p, d} \frac{\partial T}{\partial r}\right|_{r=r_{o}}=-h_{o}\left[T-T_{\text {oil }}\right] \\
& t=0:\left.\quad \mathrm{T}(r, z, t)\right|_{t=0}=T_{0}
\end{aligned}
$$

In order to ensure the stability of multi-disc temperature simulation, the heat conduction control equation and boundary conditions are discretized by a completely implicit method. Using Matlab programming, the temperature field is numerically solved.

Table 2. Material thermophysical parameters.

\begin{tabular}{|l|l|l|}
\hline \multicolumn{1}{|c|}{ Material } & SPCC & cu-pm \\
\hline Modulus of elasticity $\boldsymbol{E} / \mathbf{P a}$ & $209 \times 10^{9}$ & $100 \times 10^{9}$ \\
\hline Poisson ratio $\boldsymbol{v}$ & 0.27 & 0.275 \\
\hline $\begin{array}{l}\text { Thermal expansion coefficient } \\
\boldsymbol{\alpha} / \mathbf{K}-\mathbf{1}\end{array}$ & $\begin{array}{l}1.16 \times 10^{-} \\
5\end{array}$ & $\begin{array}{l}1.71 \times 10^{-} \\
5\end{array}$ \\
\hline Thermal conductivity $\boldsymbol{\lambda} /(\mathbf{W} / \mathbf{m K})$ & 50 & 43 \\
\hline Density $\boldsymbol{\rho} /(\mathbf{K g} / \mathbf{m} 3)$ & 7850 & 6700 \\
\hline Specific heat $\boldsymbol{C} /(\mathbf{J} / \mathbf{K g K})$ & 470 & 460 \\
\hline
\end{tabular}

\section{Test analysis}

As shown in Fig. 5, the clutch test bench includes: motor, hydraulic station, clutch test box, flywheel, brake, data acquisition control system and sensors. The motor provides driving force and makes the friction discs sliding at a constant speed. The inner friction elements of the clutch case are arranged in accordance with Fig.1. The hydraulic station provides engaging pressure and cooling lubricant for the clutch case. In order to facilitate the collection of the temperature signal of the plate, the brake keeps the plates on the driven shaft stationary.

The plate 2 and plate 4 are selected as the tested parts, on which the radial temperature measuring points are arranged. Three radial long holes are drilled in the middle of the thickness of the plate in the circumferential direction with depths of $4 \mathrm{~mm}, 20 \mathrm{~mm}$, and $36 \mathrm{~mm}$, respectively, and the thermocouple sensor is buried.

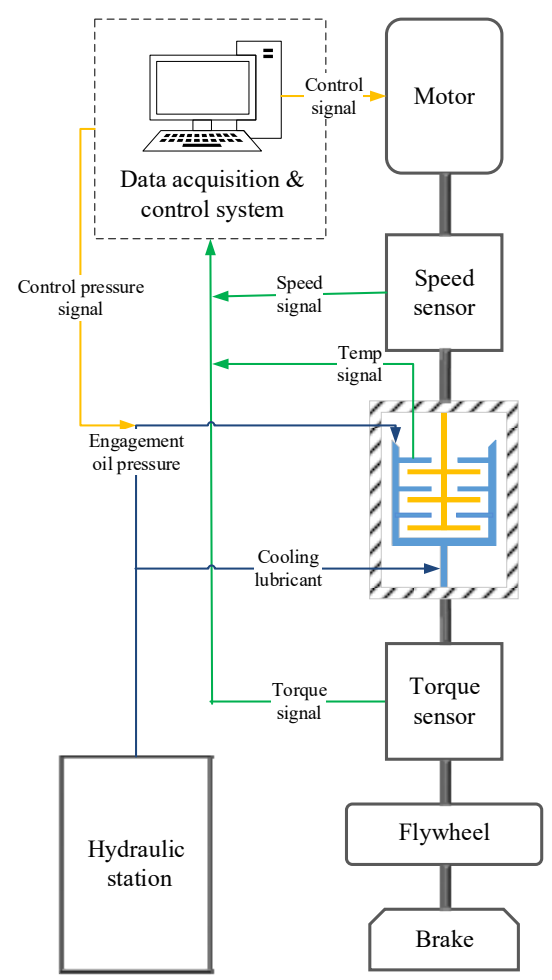

Fig. 5. Schematic diagram of the clutch test bench.

The test simulates the worming condition of the vehicle, under which, the clutch is half-engaged and the vehicle is moving forward slowly. Therefore, the effect of thermoelastic deformation is neglected, and the contact pressure is taken as a main factor of heat generation. The clutch has a rotational speed difference of $100 \mathrm{r} / \mathrm{min}$ and a pressure amplitude of $0.06 \mathrm{MPa}$.

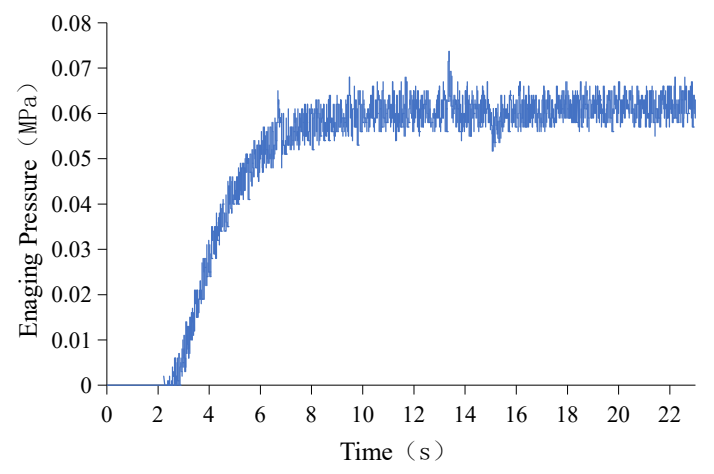

Fig. 6. Test engaging pressure curve. 


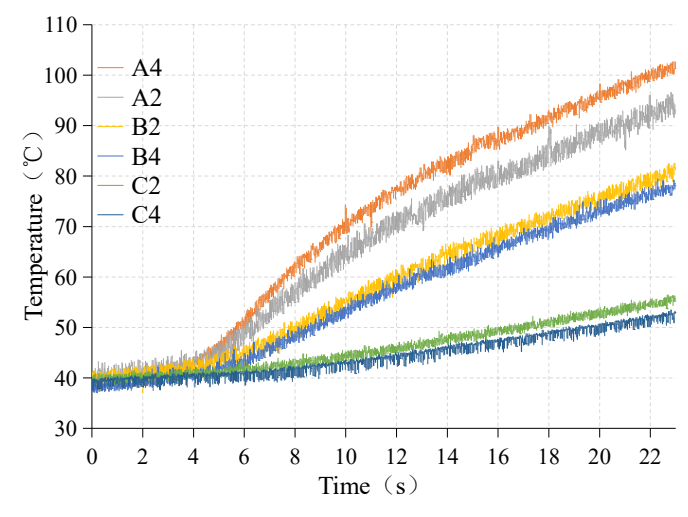

Fig. 7. Radial measuring point temperature of separate plate.

As can be seen from the Fig.6, the test duration is $23 \mathrm{~s}$. The test rig started to establish the pressure from about $2.75 \mathrm{~s}$, and the initial temperature is about $40{ }^{\circ} \mathrm{C}$. Since the pressure control valve cannot achieve the stepping action, it takes about 5 seconds to build the pressure.

As shown in Fig.7. A, B and C represent the radial measuring points of external, middle and inner diameter respectively. Subscript 2 and 4 represent plate 2 and plate 4 respectively. It was found that the temperature $T_{A 4}$ was significantly higher than $T_{A 2}, 101.3 \mathrm{C}$ and $94.7{ }^{\circ} \mathrm{C}$, respectively. $T_{B 4}$ was slightly lower than $T_{B 2}, 77.9^{\circ} \mathrm{C}$ and $79.6^{\circ} \mathrm{C}$, respectively. And $T_{A 4}$ was slightly lower than $T_{A 2}, 52.5^{\circ} \mathrm{C}$ and $54{ }^{\circ} \mathrm{C}$, respectively.

\section{Temperature simulation}

According to Fig. 6, assuming that the total effective sliding time of the simulation is $20 \mathrm{~s}$, the test interval of $2.75 \mathrm{~s} \sim 22.75 \mathrm{~s}$ is intercepted. Fitting the test pressure curve, the function of the engaging pressure is obtained.

$$
\begin{aligned}
& p(t)=\left(-18.75 t^{6}+70.43 t^{5}-108.64 t^{4}\right. \\
& \left.+88.63 t^{3}-40.56 t^{2}+9.885 t+0.0064\right)
\end{aligned}
$$

In short term engagement, the finite heat conduction and heat dissipation of the circlip and spline teeth are neglected. Importing pressure data $p(r)$ and $p(t)$ into the temp-model, results are as follows:

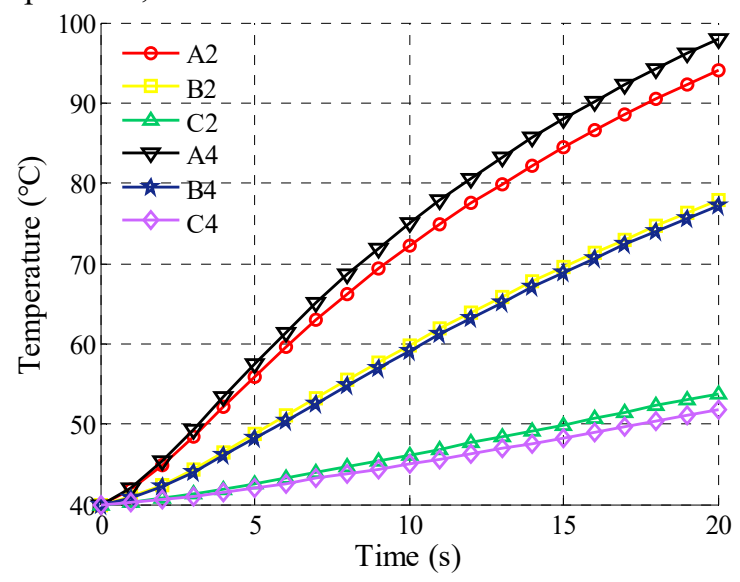

Fig. 8. Radial measuring point temperature simulation curve.

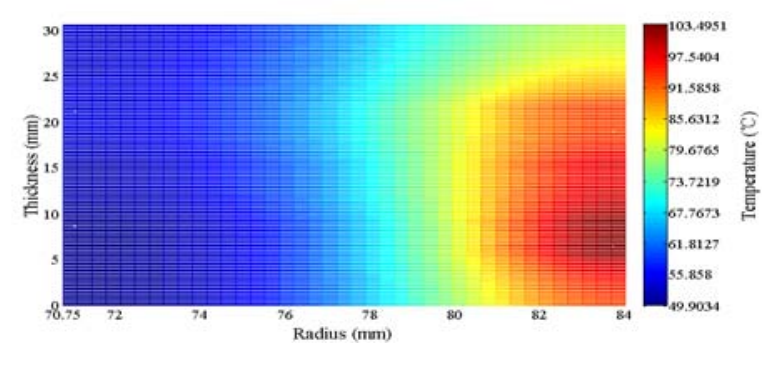

Fig. 9. Axial temperature field.

As shown in Figure 8, the simulated temperatures $T_{A 4}$ are obviously higher than $T_{A 2}, 98{ }^{\circ} \mathrm{C}$ and $97.1{ }^{\circ} \mathrm{C}$ respectively; $T_{B 4}$ is slightly lower than $\mathrm{T}_{\mathrm{B} 2}, 77.2^{\circ} \mathrm{C}$ and $77.8^{\circ} \mathrm{C}$ respectively; $T_{C 4}$ is slightly lower than $T_{C 2}, 51.8^{\circ} \mathrm{C}$ and $53.8^{\circ} \mathrm{C}$ respectively. $\mathrm{T}_{\mathrm{B}}$ and $\mathrm{T}_{\mathrm{C}}$ is close to the test result. The error of $\mathrm{T}_{\mathrm{A}}$ between simulation value and experimental value is about $3.3 \%$. The slope of simulated curve increases first, then decreases, and finally tends to be stable,coinciding with the test curve. Therefore, the simulation is correct.

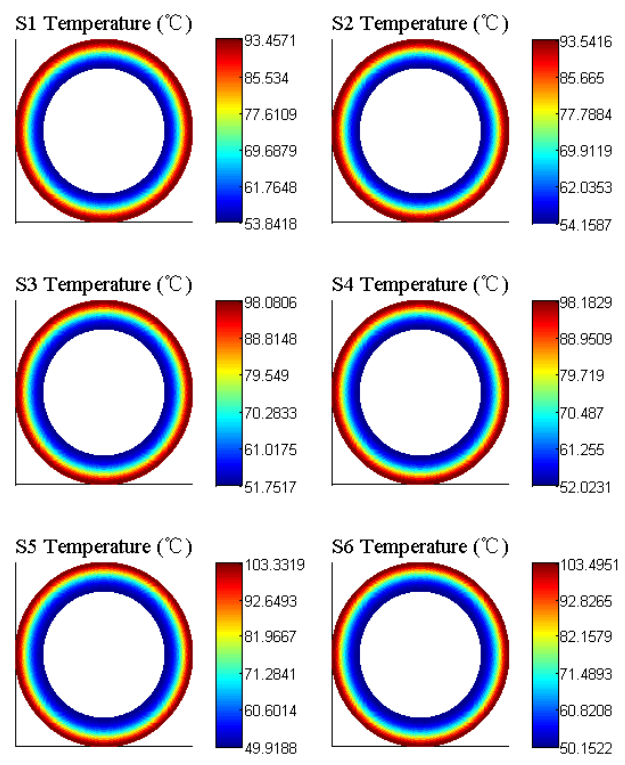

Fig. 10. Radial temperature field of sliding surface.

As shown in Fig. 9 and 10, the highest temperature zone appears on the outer diameter of S6.Compared with test, it proves that there is a difference in temperature between different plates, and the radial temperature difference is obvious under the actual constraints. Plate 4 near the concentrated load on the outer ring has a higher temperature on outer diameter, a lower temperature on inner diameter, and a larger radial temperature difference.

\section{Effect of piston pressure distribution on temperature field}

It can be seen from the above section that the constraint will make the temperature field distribution uneven. In order to avoid warp and thermal failure, the constraint form should be adjusted to make the temperature field more uniform. The position of the circlip is not easy to 
change. In addition to the uniform pressure of the piston, the finger-type piston is also a common form of restraint. Fig. 11 shows several piston pressure application options.

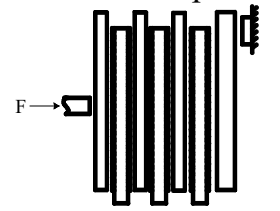

(a) middle finger

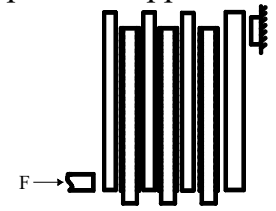

(c) internal finger

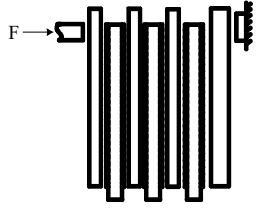

(b) external finger

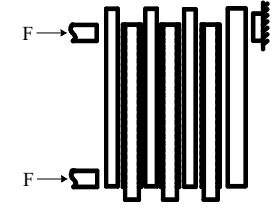

(d) double finger
Fig. 11. Four kinds of piston schemes.

In order to ensure that the friction pair transmission capacity is constant, the engaging force is recalculated by action radius. The results are shown in Fig. 12-15.

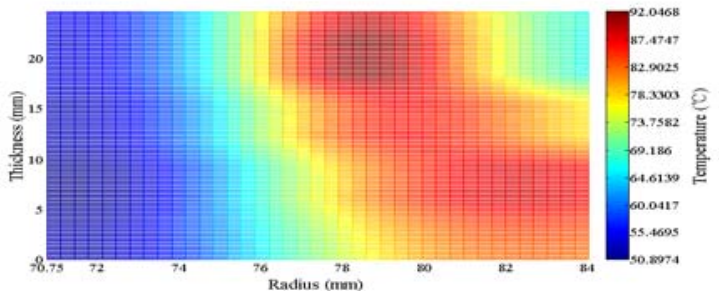

Fig. 12. Temperature field under middle finger pistion.

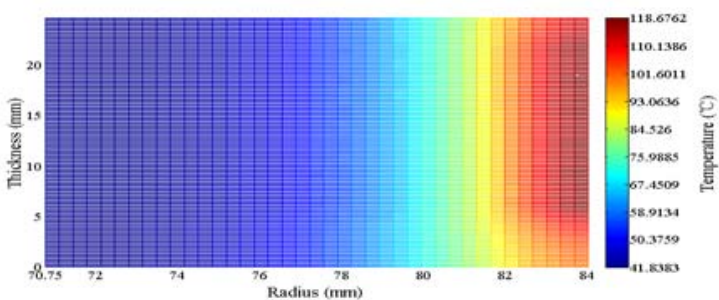

Fig. 13. Temperature field under external finger piston.

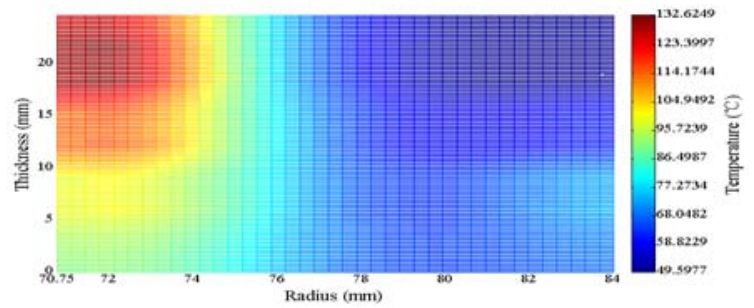

Fig. 14. Temperature field under internal finger piston.

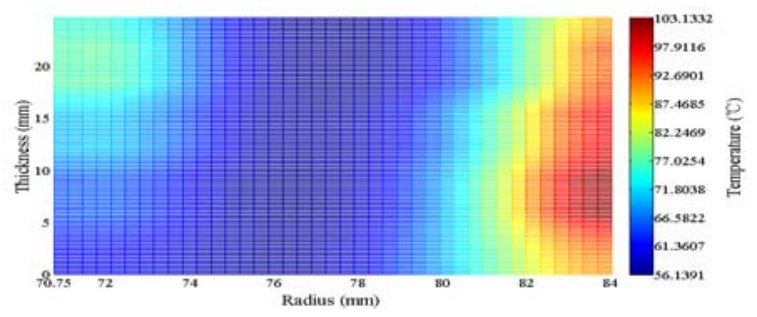

Fig. 15. Temperature field under double fingers piston.

It can be seen from Fig. 12-15 that the highest temperature zone on the each component is close to the location where the concentrated load is constrained.

Table 3. Temperature under five constraint schemes.

\begin{tabular}{|c|c|c|c|c|c|}
\hline Schemes & $\mathrm{a}$ & $\mathrm{b}$ & $\mathrm{c}$ & $\mathrm{d}$ & $\mathrm{e}$ \\
\hline $\begin{array}{c}\text { Maximum temp } \\
\mathbf{T}_{\mathbf{m a x}} /{ }^{\circ} \mathrm{C}\end{array}$ & 91.7 & $\begin{array}{c}118 . \\
7\end{array}$ & $\begin{array}{c}132 . \\
6\end{array}$ & $\begin{array}{c}103 . \\
1\end{array}$ & $\begin{array}{c}103 . \\
5\end{array}$ \\
\hline $\begin{array}{c}\text { Maximum radial } \\
\text { temp difference } \\
\mathbf{T}_{\text {rmax }} /{ }^{\circ} \mathrm{C}\end{array}$ & 38 & 76.8 & 82.8 & 46.7 & 53.3 \\
\hline $\begin{array}{c}\text { Maximum axial } \\
\text { temp difference } \\
\mathbf{T}_{\mathbf{z m a x}}{ }^{\circ} \mathrm{C}\end{array}$ & 20 & 0 & 32.8 & 12.5 & 10 \\
\hline
\end{tabular}

Table 3 compares five plans. Scheme (e) is the scheme with uniform pressure. In the case of circlip, the temp rise and radial temp difference caused by scheme (a) are the lowest, whose temperature field is the most uniform.

Scheme (d) and scheme (e) are the second.These schemes can effectively reduce the temperature difference between the components.

The results of schemes (b) and (c) are the worst, whose radial temp difference is more than twice of (a).

\section{Conclusion}

In this paper, two-dimensional pressure model and thermal analysis model of wet multi-disc clutch are established in Abaqus and Matlab respectively by combining finite element method and implicit difference method. The temperature distribution of friction pair in worming condition under actual constraints is solved. Through bench test, five different restraint schemes are analyzed to improve the temperature rise and temperature difference of multi-disc clutch. The conclusions are as follows:

The pressure on each side of the multiple friction pairs is different, significantly different from the positive piston pressure, and unevenly distributed on component under the action of the circlip and the piston. Therefore, the effect of multiple pairs and restriction of piston and circlip can not be ignored in thermal analysis of friction pairs.

Under the influence of multiple pairs and nonuniform load, the high temperature and high pressure areas will be close to the concentrated load, resulting in a significant radial temperature difference on components near the concentrated load. 
The temperature rise and radial temperature difference of the clutch produced by the middle fingertype scheme in which the piston pressure is concentrated on the middle diameter is lowest of five schemes.

The authors would like to thank the Zhuhai Huayue Transmission Technology Co., Ltd. for supporting this research project.

\section{References}

1. P. Zagrodzki, Analysis of Thermomechanical Phenomena in Multidisc Clutches and Brakes, Wear 140, 291-308 (1990)

2. X. Liu, K. Shang, Z. Wang, et al, Temperature Modeling and Temperature Field Simulation for Disc Brakes, Automotive Engineering 38, 453-505 (2016)

3. L. Wu, and Y. Qi, High Accuracy Finite Difference Method for Three Dimensional Heat Conduction
Equation, Mathmatics in Practice and Theory 47, 187-195 (2017)

4. Chen Youfei, Li Liang, Yang Cai, et al, Research on Finite Difference Simulation Model of Brake Thermal Analysis, Automotive Engineering 34, 236240 (2012)

5. J. Zhang, B. Ma, Y. Zhang, et al, Analysis of Factors Affecting Temperature Field and Stress Field of Wet Shift Clutch, Journal of Beijing Institute of Technology 30, 660-664 (2010)

6. Z. He, H. Lv, T. Lin, et al, Thermal structure coupling analysis of wet multi-disc friction clutch connection process, Mechanical Research and Application 5, 47-50 (2010)

7. S. Yang,W. Tao, Heat Transferology, 28-29 (2008)

8. M. Ingram, J. Noles, R. Watts, et al, Frictional properties of automatic transmission fluids, part 1:measurement of friction-sliding speed behavior, Tribology Transactions 54, 145-153 (2010) 